\title{
Innovative Assisted Living Tools, Remote Monitoring Technologies, Artificial Intelligence-Driven Solutions, and Robotic Systems for Aging Societies: Systematic Review
}

\author{
A Hasan Sapci ${ }^{1 *}$, MD; H Aylin Sapci ${ }^{*}, \mathrm{MD}$ \\ ${ }^{1}$ Adelphi University, Garden City, NY, United States \\ *all authors contributed equally
}

Corresponding Author:

A Hasan Sapci, MD

Adelphi University

1 South Avenue, Nexus Building

Garden City, NY, 11530

United States

Phone: 15168338156

Email: sapci@adelphi.edu

\section{Abstract}

Background: The increase in life expectancy and recent advancements in technology and medical science have changed the way we deliver health services to the aging societies. Evidence suggests that home telemonitoring can significantly decrease the number of readmissions, and continuous monitoring of older adults' daily activities and health-related issues might prevent medical emergencies.

Objective: The primary objective of this review was to identify advances in assistive technology devices for seniors and aging-in-place technology and to determine the level of evidence for research on remote patient monitoring, smart homes, telecare, and artificially intelligent monitoring systems.

Methods: A literature review was conducted using Cumulative Index to Nursing and Allied Health Literature Plus, MEDLINE, EMBASE, Institute of Electrical and Electronics Engineers Xplore, ProQuest Central, Scopus, and Science Direct. Publications related to older people's care, independent living, and novel assistive technologies were included in the study.

Results: A total of 91 publications met the inclusion criteria. In total, four themes emerged from the data: technology acceptance and readiness, novel patient monitoring and smart home technologies, intelligent algorithm and software engineering, and robotics technologies. The results revealed that most studies had poor reference standards without an explicit critical appraisal.

Conclusions: The use of ubiquitous in-home monitoring and smart technologies for aged people's care will increase their independence and the health care services available to them as well as improve frail elderly people's health care outcomes. This review identified four different themes that require different conceptual approaches to solution development. Although the engineering teams were focused on prototype and algorithm development, the medical science teams were concentrated on outcome research. We also identified the need to develop custom technology solutions for different aging societies. The convergence of medicine and informatics could lead to the development of new interdisciplinary research models and new assistive products for the care of older adults.

(JMIR Aging 2019;2(2):e15429) doi: 10.2196/15429

\section{KEYWORDS}

innovative assisted living tools for aging society; artificially intelligent home monitoring; older adults; robotic technologies; smart home

\section{Introduction}

Life expectancy has increased worldwide, and countries have been experiencing the same challenges regardless of the geographical location. According to the US Census Bureau, the population aged $\geq 65$ years is expected to double over the next three decades and reach 83.7 million [1]. One of the most significant challenges of the aging population is that the 
incidence of chronic conditions such as dementia, Alzheimer disease, congestive heart failure, and cancer and the need for medical attention have increased. However, rapid advances in technology have revolutionized medicine along with health care for the elderly.

Using a personal computer, remote patient monitoring device, smartphones, and mobile apps to improve the quality of the older persons' lives was not an option in the past. Each new technology enabled researchers and clinicians to develop new disease management protocols, especially for frail elderly people with chronic diseases and dementia. Recent randomized controlled trials and systematic reviews have documented that remote monitoring reduces specific 30-day hospital readmission and mortality rates [2,3]. Aging in place is defined as "remaining living in the community, with some level of independence, rather than in residential care" [4]. Although technology usage is limited among seniors aged $\geq 75$ years, several prototype and experimental systems were developed, and various studies were conducted to support the elderly by clinicians, computer scientists, data scientists, and engineers; however, few studies explored the current trends in senior care technology research [5]. Therefore, the aim of this study was to explore the current research trends and level of evidence for remote patient monitoring, smart home, and artificially intelligent monitoring systems.

\section{Methods}

\section{Study Design}

The literature search was conducted in February 2019. Remote monitoring and intelligent health care technologies research conducted in both health care and technology disciplines as well as the following literature repositories were chosen for the search: Cumulative Index to Nursing and Allied Health Literature Plus, MEDLINE, EMBASE, Institute of Electrical and Electronics Engineers Xplore, ProQuest Central, Scopus, and Science Direct.

A variety of synonymous terms were combined using Boolean logic, and a combination of three groups of keywords-(1) elderly, (2) home care, and (3) assistive technology-was selected as the keywords. To include all relevant publications, their thesaurus equivalent words and associated Medical Subject Headings terms - aging, aged, telemedicine, elderly people, nursing home, home health care, independent living, ambient assistive living, smart home technology, self-help devices, and artificial intelligence (AI) in older people's care-were also included in the search (Table 1). We analyzed each article by the level of evidence and study type, objectives, and highlights. A combination of quantitative and qualitative approaches was used in the data analysis.

Table 1. Keywords and synonyms.

\begin{tabular}{ll}
\hline Keyword & Synonyms \\
\hline Elderly & Aging $(\mathrm{MeSH})^{\mathrm{a}}$ or Aged (MeSH) or Elderly People \\
Home care & Nursing Home (MeSH) or Home Health Care or Independent Living (MeSH) \\
Assistive technology & $\begin{array}{l}\text { Ambient Assistive Living or Smart Home Technology or Telemedicine (MeSH) or Assistive Technology or Self-Help } \\
\text { Devices }(\mathrm{MeSH}) \text { or Artificial Intelligence (MeSH) in Eldercare }\end{array}$ \\
\hline
\end{tabular}

${ }^{\mathrm{a}} \mathrm{MeSH}$ : Medical Subject Headings.

\section{Inclusion and Exclusion Criteria}

Quantitative, qualitative, and mixed method peer-reviewed publications and published conference papers were included. Research articles and case reports related to assistive technology assessment for elderly care, set in homes, smart homes, experimental settings, nursing homes, and rehabilitation settings were selected.

The inclusion and exclusion criteria are listed in Textboxes 1 and 2 , respectively.

Textbox 1. Inclusion criteria.

- Published after January 2000 in English language

- Peer-reviewed journal articles and published conference papers

- Studies that focused on the latest technological, artificial intelligence, and complex software algorithms solutions for elderly care and novel assistive technologies and independent living

- Studies set in homes, smart homes, experimental laboratory settings, nursing homes, or rehabilitation settings

- Publications related to older people's care, independent living, and novel assistive technologies

Textbox 2. Exclusion criteria.

- $\quad$ Published before January 2000 in languages other than English

- Literature reviews and systematic reviews

- Book chapters, dissertations, theses, magazine articles, reports, wire feeds, position papers, editorials, white papers, and working papers 


\section{Study Selection}

A total of 1721 publications were found at the end of the initial search of the selected databases. Search strings and return values for each database are listed in Textbox 3 and Table 2, respectively. The list was filtered by removing duplicates, the remaining abstracts were assessed, and the publications that did not meet the inclusion and exclusion criteria were excluded. At the end of this process, 91 eligible publications for inclusion were identified. Figure 1 displays the search diagram and the number of articles assessed at each stage of the review.

Textbox 3. Search string.

(“Aging” OR "Aged" OR "Elderly People”) AND (“Nursing Home” OR "Independent Living”) AND (“Self-Help Devices" OR "Telemedicine” OR "Ambient Assistive Living" or "Service Robot")

Table 2. Search queries and return values.

\begin{tabular}{ll}
\hline Database name & Return value (n) \\
\hline Cumulative Index to Nursing and Allied Health Literature Plus & 93 \\
MEDLINE & 159 \\
EMBASE & 279 \\
Institute of Electrical and Electronics Engineers Xplore & 31 \\
ProQuest Central & 747 \\
Scopus & 352 \\
Science Direct & 60 \\
\hline
\end{tabular}


Figure 1. Search methodology. CINAHL: Cumulative Index to Nursing and Allied Health Literature; IEEE: Institute of Electrical and Electronics Engineers.

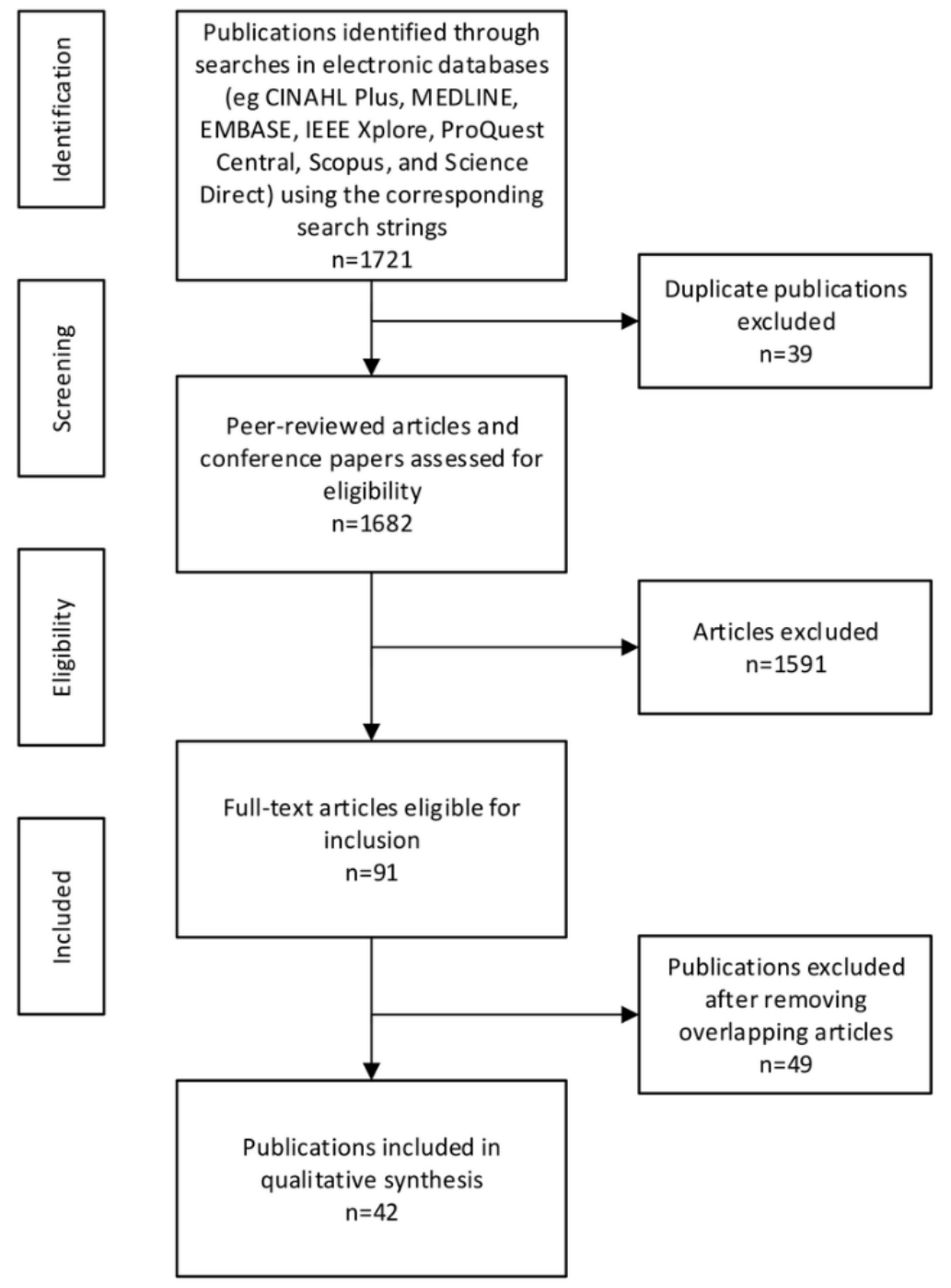

\section{Results}

Analysis of the 91 full articles revealed innovative technologies that were developed to monitor older people's activities using various sensors, telemedicine, assistive robots, and remote monitoring devices. Multimedia Appendix 1 lists the characteristics and highlights of the included studies [6-86].

Our review determined that the studies either focused on technology acceptance or examined the development of new patient monitoring and smart home technologies, real-time transmission of raw data, and AI algorithms. In the publications reviewed, most articles were qualitative, and only five studies were randomized controlled trials. First, we categorized the articles by types of study design. Most studies were quasi-experiment $(n=43)$ and case reports $(n=39)$. The others were case-control studies $(n=3)$, cohort studies $(n=1)$, and randomized controlled trials $(n=5)$. The number and percentage of these articles are listed in Table 3.

Second, we evaluated the levels of evidence of each article. The Oxford Centre for Evidence-Based Medicine levels rates evidence based on the study design, rigor, and validity and judges the strength of evidence in a technically accurate and easily understandable manner. Therefore, this well-established and accepted standard was selected to determine the level of evidence [87]. The majority of the articles were listed as Level IV evidence that represents poor or nonindependent reference standards (49/91, 49\%). Only 6\% (6/91) of articles were listed as Level I evidence, which represents the studies with good reference standards. The classification of publications by levels of evidence is shown in Table 4.

Third, to determine the current status and future challenges of disruptive technologies to support independent living, the selected articles were analyzed with regard to study objectives. Figure 2 summarizes the focus of the articles evaluated. Of 91 articles, the majority were focused on older adults' acceptance and adoption of monitoring technology $(\mathrm{n}=17)$, smart home and telemedicine apps $(n=16)$, robotic technologies $(n=14)$, and usability evaluation $(n=11)$. Many researchers evaluated novel remote monitoring technologies $(n=10)$ and artificially intelligent assistive technologies $(n=9)$. The remainder of the publications were about pattern recognition $(n=6)$, wearable and mobile technologies $(n=5)$, context-aware framework $(n=2)$, and privacy considerations $(n=1)$. 
Fourth, as there is no widely accepted classification system to evaluate elderly care research that focuses on technology solutions, we conducted a thematic analysis, removed overlapping articles, identified 42 publications, and analyzed each device and app. Braun and Clarke [88] thematic analysis method was used to determine the patterns.
Finally, the studies that represent evolving topics were identified, and four themes emerged: technology acceptance and readiness, novel patient monitoring and smart home technologies, intelligent algorithm and software engineering, and robotics technologies (Multimedia Appendix 2) [6-29,56,57,65,73,103].

Table 3. Study types (N=91).

\begin{tabular}{lr}
\hline Category & Articles, n (\%) \\
\hline Case report & $39(42)$ \\
Case-control study & $3(3)$ \\
Cohort study & $1(1)$ \\
Quasi-experiment & $43(47)$ \\
Randomized controlled trial & $5(5)$ \\
\hline
\end{tabular}

Table 4. Levels of evidence (N=91).

\begin{tabular}{ll}
\hline Category & Articles, $\mathrm{n}(\%)$ \\
\hline I & $5(5)$ \\
II & $6(6)$ \\
IV & $45(49)$ \\
V & $35(38)$ \\
\hline
\end{tabular}

Figure 2. Study by research focus.

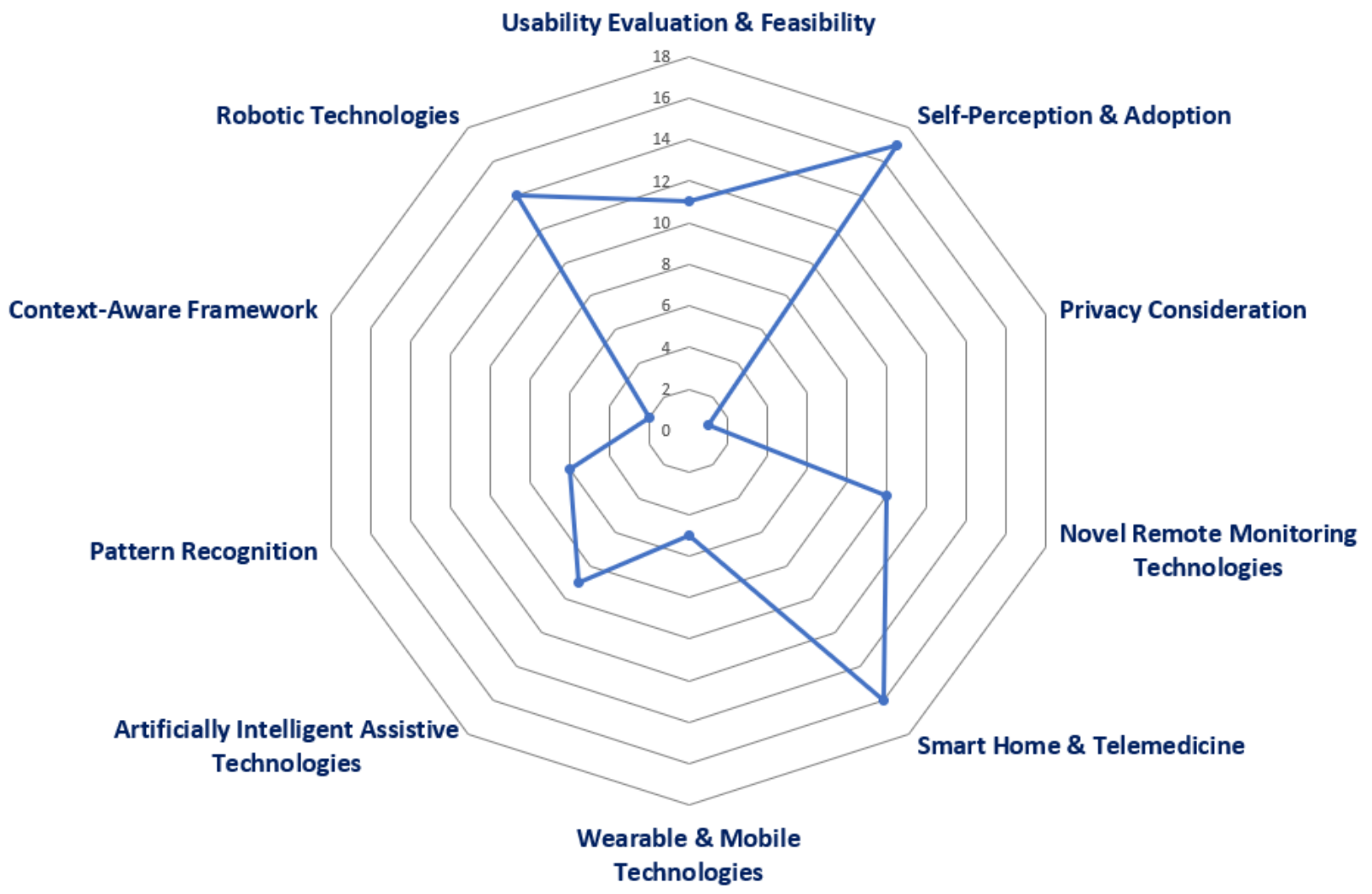




\section{Technology Acceptance and Readiness}

\section{Overview}

This theme encompasses studies related to technology adoption. Researchers investigated older adults' willingness to accept contactless monitoring technologies, specific electronic health system, and smart home-based technologies such as bed, motion, kitchen safety, and fall detection sensors [6-8].

In addition to technology adoption, some studies explored perceived usefulness of telehealth kiosk-telehealth care systems that measure bed and chair occupation and detect falls, privacy concerns of in-home monitoring systems, older people's attitudes toward assistive telemonitoring systems, acceptability of home monitoring technologies, and video-based monitoring technologies that capture data about daily activities [9-89]. Caregivers' acceptance of home telecare technologies was also investigated along with wearable and ambient technologies $[14,15]$

\section{Novel Patient Monitoring and Smart Home Technologies}

This theme comprises sophisticated systems that consist of home service robot; home and body sensor network; mobile device; cloud servers and remote caregivers; supervised machine learning approach and context-based reasoning to perform a clinical assessment of dementia; proof-of-concept platforms that consists of a Zigbee network, sensors, a home client, and remote server; and novel protocols over SMS to monitor elderly and alert caregivers when a fall occurs [90-92].

Common denominators for smart home for health care, robotics, wearable and mobile systems, and telemedicine apps were determined by analyzing each device and app. Our study revealed that researchers who focused on smart homes preferred novel sensor systems and ultrasonic receivers and transmitters for their study, and those who focused on remote monitoring preferred custom wearable devices and telemedicine equipment (Figure 3).

Figure 3. Technologies used for aging societies. RF: radio frequency.

\section{Smart home for health care and robotics systems}

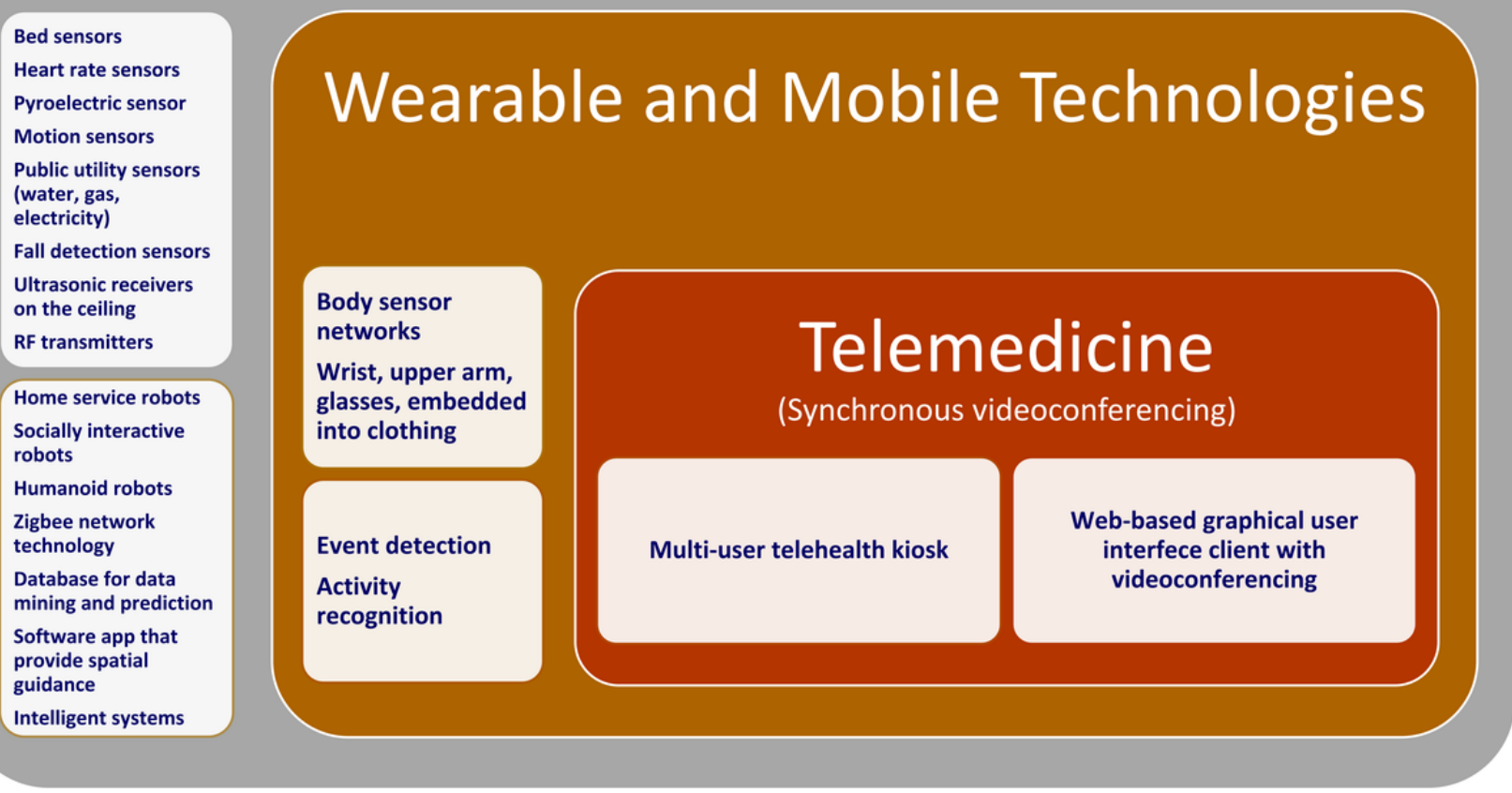

In Europe, an international experimental Ambient Assisted Living project called Enhanced Complete Ambient Assisted Living Experiment successfully tested fall detection, activity classification, and energy expenditure algorithms to monitor patients' activity and reduce morbidity and mortality [17]. Another novel technology explored by researchers was virtual reality (VR), and new technologies about the display quality, presence, user input, fidelity, and usability of virtual experiences demonstrated effectiveness to assess functional behavior and emphasized the potential of VR technology to empower dementia patients [18].
Several experimental prototype devices were also developed to monitor elderly patients' progress and treatment. With regard to innovative low-cost Bluetooth-enabled technologies, some researchers developed a telediagnosis system for early detection of Alzheimer disease and captured the movement patterns [93]. A Web-based home monitoring system using wearable sensors was developed for patients with Parkinson disease [94].

A randomized controlled trial was designed to evaluate the Integrated Telehealth Education and Activation of Mood project's clinical outcomes and demonstrated that the integration 
of telemonitoring intervention improved geriatric home care patients' problem-solving skills and self-efficacy in managing their chronic illness [19]. In a different study, a sensor network system that comprised ultrasonic receivers, signal generators, radio frequency transmitters, ultrasonic $3 \mathrm{D}$ tags, and a computer successfully detected the accident-prone events in advance [95].
The increasing availability of the broadband internet, cellular communication technologies, internet of things apps that connect multiple devices and the decreasing cost of sensors have transformed various industries and markets. Our study demonstrates the potential of novel platforms that can improve assisted living and elderly care (Figure 4).

Figure 4. Technology solutions for elderly care.

\section{Main Groups of Technology Solutions}

Novel Technologies and Solutions for Assistive Living

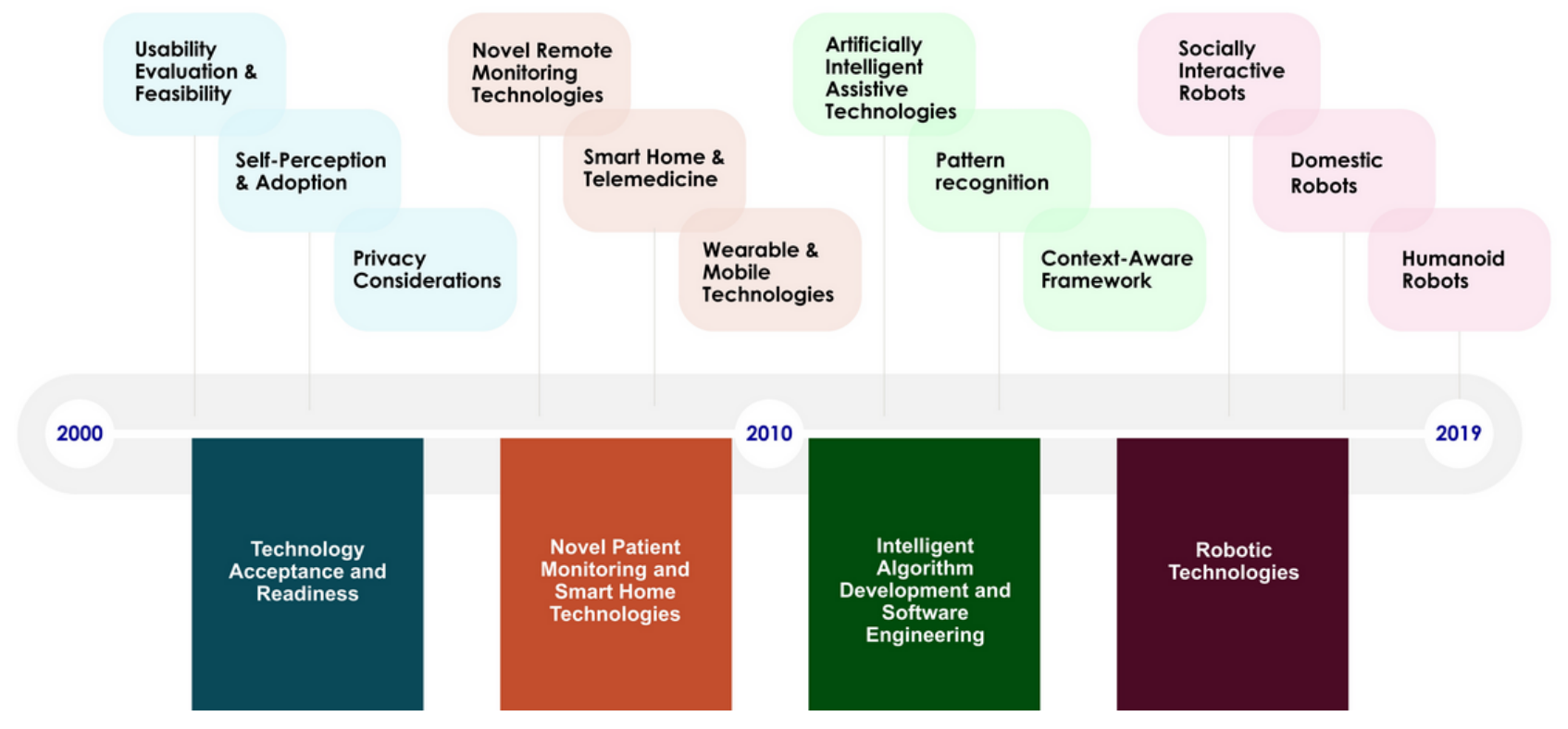

\section{Intelligent Algorithm Development and Software Engineering}

This theme comprises data mining algorithms that collect data about the environment and intelligently predict possible problems to make health care decisions, context-aware middleware to sense and respond to the user's environment, pyroelectric sensors, and infrared optoelectronic components designed to detect electromagnetic radiation and analyze the reasoning process in order to detect elderly people's activity [21-96].

Some researchers developed predictive models and reported the optimal classifier of assistive technology adoption for people with dementia [22]. Another proof-of-concept navigation system based on augmented reality successfully generated a route to a specific destination based on the user context including well-known places, social relationships, and point of interest (Figure 4) [23]. In information science, the term ontology encompasses entities, relations, functions, axioms, and instances. Ontology-based models combine data from multiple sources [97]. Researchers designed and successfully tested an ontology-based prototype knowledge system that can collect data from an RGB camera, 3D depth camera, and microphones [98].

Figure 5 summarizes the AI algorithms used for independent living apps. Most AI studies focused on instance-based algorithms, decision tree, Bayesian algorithm, clustering, association rule learning, artificial neural network, and deep learning algorithms. 
Figure 5. Artificial intelligence algorithms for independent living.

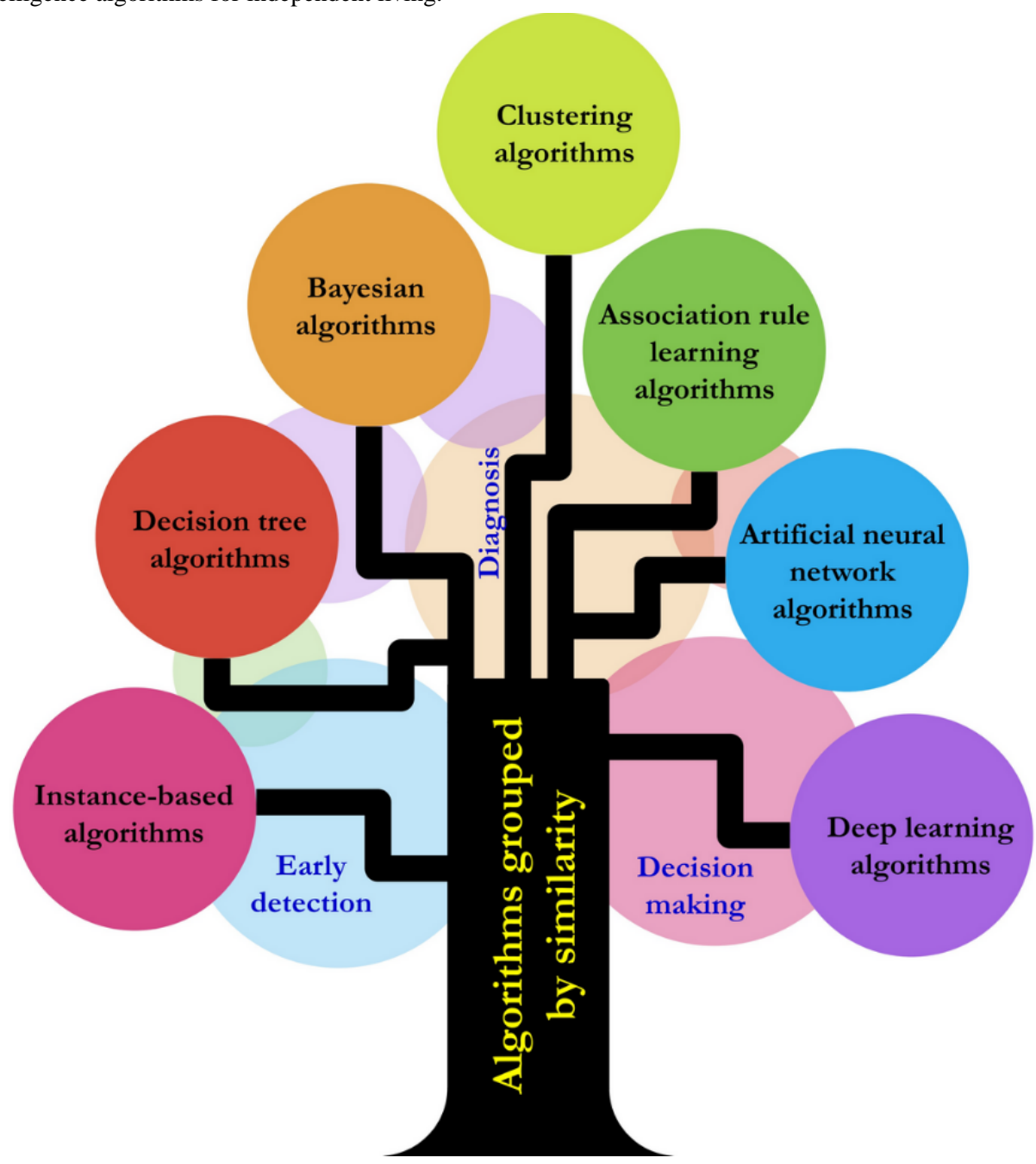

\section{Robotics Technologies}

This theme encompasses various robotic technologies that affect elderly care. Although some studies investigated a range of advanced AI technologies [24,99], others examined simple versions to evaluate robot-assisted activities. The increasing number of individuals that require rehabilitation and assistance has driven innovators to develop new robotics systems that can be integrated with elderly care solutions. Telepresence, companion, home automation and service, rehabilitation and health monitoring, and reminder robots can assist individual living.

The researchers who assessed AI technology for domestic assistive services developed eight different scenarios to understand the usefulness of the domestic robot in everyday situations and partially validated their results with experiments involving 100 participants [100]. Other researchers who evaluated robotic technologies used commercially available robots with tactile, light, and posture sensors and focused on studies about socially interactive robots. Similarly, a team of researchers in Japan developed a partner robot to relieve the solidarity feeling of elderly through conversation, quizzes, tongue twisters, and arithmetic calculations, and the experimental results were found to be promising [25].
Telepresence robots are remote-controlled devices that a user can drive from a different location and communicate with a remote site using the integrated videoconferencing systems.

A team of researchers used a sensor network infrastructure that comprised pressure monitor, glucose, weight, and oxygen sensors integrated with a telepresence robot. The project received support from the European Commission and deployed in real homes across Europe [26]. Another multidisciplinary effort to develop a mobile robotic assistant was the Pearl project. Researchers from the University of Michigan, University of Pittsburgh, and Carnegie Mellon University developed an autonomous robot to provide cognitive orthotic functions and tested it in a residential retirement community successfully [27].

Interestingly, some studies did not find any difference between a therapeutic robocat and plush cats, and others emphasized technical challenges of intelligent modular service mobile robots that comprised tactile, infrared, and ultrasound sensors; Kinect and voice generation; and recognition systems [24,101] Robots may also not be the best solution for certain care-related activities. A remote-controlled Spykee robot was used to make home hazard assessments for fall preventions, and it did not find an agreement between the robot and in-person video assessment [28]. A recent study conducted in Europe evaluated a software framework's efficiency using a humanoid robot and 
validated each solution's efficiency using simulation and real case experiments [99].

This study revealed the multidisciplinary aspect of robotic technology and the development of autonomous mobile robots that can interact with elderly people and provide therapeutic benefits. The implementation of autonomous robots in elderly care requires collaboration among academic institutions, clinicians, and industry players and a focus on continuously improving the health care experience.

\section{Discussion}

\section{Principal Findings}

The purpose of this literature review was to determine the best available evidence about the development and implementation of technological solutions for elderly care, and in this paper, we report that the evolving technology trends can transform the aging population and ways that $\mathrm{AI}$ and pattern recognition might impact older individuals' care.

Specifically, we examined publications about intelligent remote monitoring, smart home health care, and robotic technologies to respond to the following research questions: (1) what are the current trends in aging-in-place technology research? and (2) what is the level of evidence for remote patient monitoring, smart home, and artificially intelligent monitoring systems?

To answer the first question, we determined the wide range of studies that focused on technology acceptance, novel patient monitoring and smart home technologies, intelligent algorithm development and software engineering, and robotics technologies. To answer the second question, the breakdown of the articles identified that most studies (85\%) had poor reference standards without an explicit critical appraisal (Table 3 ), and the majority of the publications were qualitative.

This literature review demonstrated that most studies between 2000 and 2010 were designed to examine older adults' perceptions of technology. Intelligent assistive technologies have changed with an unpredictable pace, and consequently, there has been an increasing interest in exploring patient monitoring and home care technologies. The studies about technology acceptance led to more sophisticated studies that used wireless monitoring devices, sensors, intelligent algorithms, and experimental or quasi-experimental research methods. Thus, these studies can be considered as the first era of technology research for the aging society (Figure 4).

After 2010, we noticed an increase in the number of studies that explored prototype system development, implementation of new smart home technologies using sensors, development of assistive robots, and design of new AI and machine learning systems to support elderly care. The advancements in technology gave the researchers the ability to develop sophisticated AI algorithms, integrate advanced context acquisition methods, and analyze and automate high-level and complex tasks. This period can be considered as the second era of technology research for aging society, as many studies documented the potential use of robotic technologies, reported encouraging adoption rates, and recommended further experimental studies.
Our analysis demonstrated that many of the studies used unique technological solutions for different elderly groups. For example, studies that support independent lifestyle were designed for older people living alone in their home, whereas studies about new technologies for dementia and patients with Alzheimer disease were designed for older people living in nursing homes.

Data generated from medical devices have been growing so fast that using manual techniques to analyze data is not an option anymore to monitor home care patients. A recently published study assessed the use of patient-generated data in clinical practice and emphasized its impact on health outcomes [102]. Over the last decade, there has been a significant increase in the number of studies that focused on AI and machine learning. Some studies investigated user perceptions, barriers, and novel system development using sensors and smart home devices, whereas others focused on the development of context-aware and adaptive technology development. This technology can be integrated into different environments; can collect specific information such as temperatures, geographic locations, and user preference; and can deliver the relevant data depending on a set of variables unique to the user. Our review also revealed that the focus of AI apps for elderly care and sophisticated algorithms could improve the accuracy and the progress of analytical techniques. Therefore, it is likely that when combined with AI apps, remote monitoring systems will work faster and make more accurate predictions.

Moreover, this study identified several studies about novel innovative systems to monitor older people's health. Many of these studies were proof-of-concept systems to demonstrate the feasibility of the proposed equipment or app. It is quite challenging to determine the benefits and long-term impact of each technology or prototype systems because some technologies might become widely adopted in time, whereas others cannot find enough support for implementation. Furthermore, designing studies to validate health care institutions', nursing homes', and individual patients' technology adoption rates for elderly care might be challenging. Thus, we recommend nationwide studies to monitor technology adoption trends. Although this is an ambitious objective for individual researchers, governments and academic research institutions can collaborate and conduct these studies.

\section{Limitations}

This study has some limitations. First, most study findings were not comparable because of the various research settings and types of technology used. Second, the majority of the studies were uncontrolled and had small user groups, and their level of evidence was between IV (45/91, 50\%) and V (35/91, 39\%). Owing to small sample sizes and methodological weaknesses in the studies, it was difficult to generalize their outcomes.

\section{Conclusions}

Medical and engineering sciences have different principles and use different approaches for assisted living, home care, and telecare innovations. It is probable that older people's care will rely more on technology-driven patient solutions and AI algorithms to determine early warning predictions and initiate the interventions at earlier stages. Hence, we also propose the 
development of custom technology solutions for different aging societies: (1) novel smart home apps and sensor-based systems for older people living alone, (2) home service robots and telemedicine apps for older people living with family members, (3) wearable and remote monitoring devices for older people living in retirement communities, and (4) technologies to assist older people with dementia living in nursing homes and assisted living facilities (Figure 6). Machine learning and AI might be embedded into any hardware device, and further study is needed to identify aging society's custom technological needs and determine AI research priorities. Taking into consideration different aging societies' custom needs will improve older people's independent living skills and elderly patients' health care outcomes.

Figure 6. Technology solutions for different aging societies.

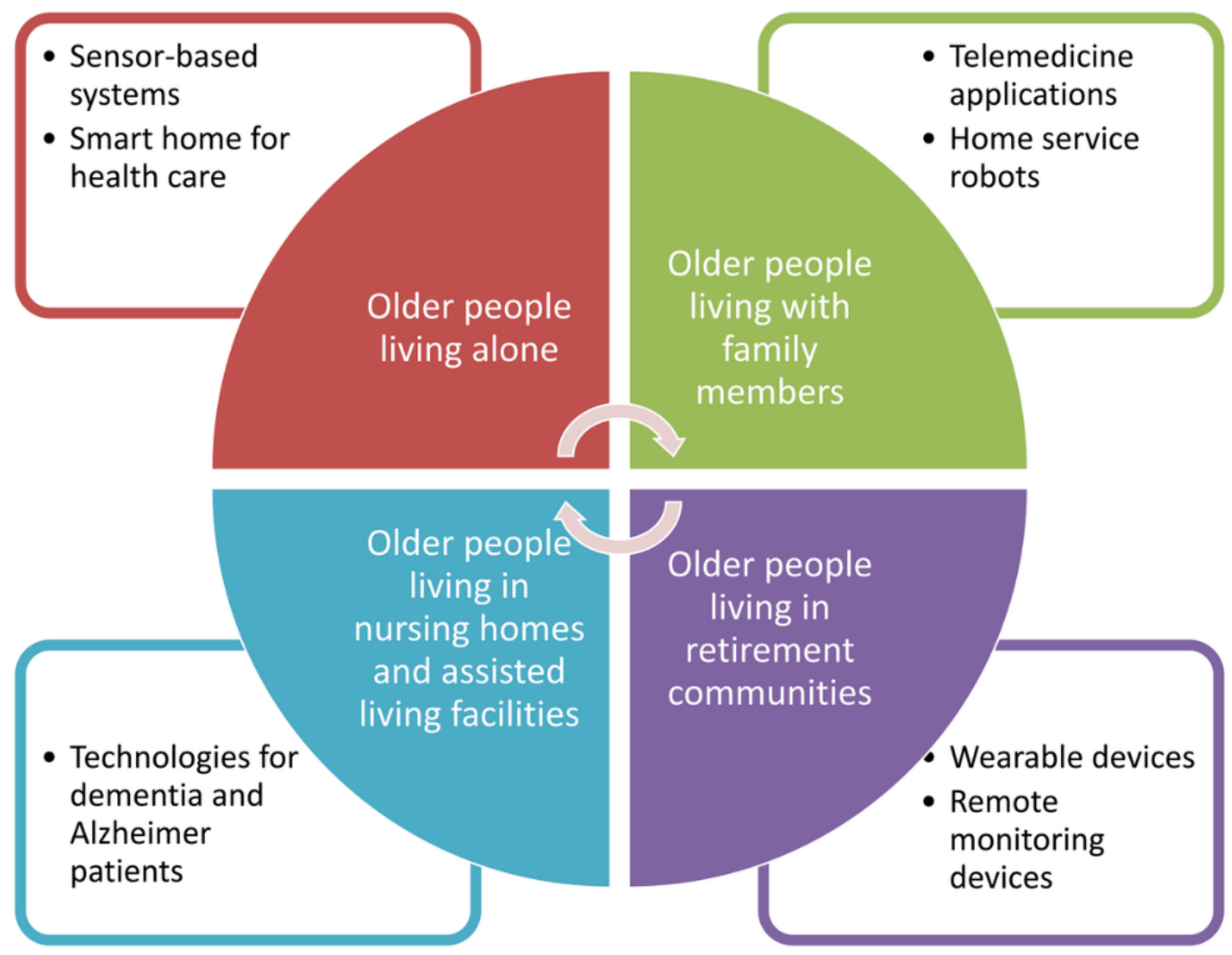

\section{Conflicts of Interest}

None declared.

\section{Multimedia Appendix 1}

Characteristics of included studies.

[DOCX File, 35 KB-Multimedia Appendix 1]

\section{Multimedia Appendix 2}

Emerging technology solutions.

[DOCX File, 18 KB-Multimedia Appendix 2]

\section{References}

1. Ortman JM, Velkoff VA. Census. 2014. An Aging Nation: The Older Population in the United States URL: https://www. census.gov/prod/2014pubs/p25-1140.pdf [accessed 2019-07-01]

2. Pekmezaris R, Tortez L, Williams M, Patel V, Makaryus A, Zeltser R, et al. Home telemonitoring in heart failure: a systematic review and meta-analysis. Health Aff (Millwood) 2018 Dec;37(12):1983-1989. [doi: 10.1377/hlthaff.2018.05087] [Medline: $\underline{30633680}$ ]

3. Blum K, Gottlieb SS. The effect of a randomized trial of home telemonitoring on medical costs, 30-day readmissions, mortality, and health-related quality of life in a cohort of community-dwelling heart failure patients. J Card Fail 2014 Jul;20(7):513-521. [doi: 10.1016/j.cardfail.2014.04.016] [Medline: 24769270] 
4. Davey J, Joux V, Nana G. The Hub: New Zealand Government. 2004. Accommodation Options for Older People in Aotearoa/New Zealand URL: https://thehub.sia.govt.nz/assets/documents/ accommodation options for older people in aotearoa new zealand.pdf [accessed 2019-07-01]

5. Anderson M, Perris A. Pew Research Center. 2017 May. Tech Adoption Climbs Among Older Adults URL: https://www. pewinternet.org/2017/05/17/technology-use-among-seniors/ [accessed 2019-07-01]

6. Claes V, Devriendt E, Tournoy J, Milisen K. Attitudes and perceptions of adults of 60 years and older towards in-home monitoring of the activities of daily living with contactless sensors: an explorative study. Int J Nurs Stud 2015 Jan;52(1):134-148. [doi: 10.1016/j.ijnurstu.2014.05.010] [Medline: 24951084]

7. Botella C, Etchemendy E, Castilla D, Baños RM, García-Palacios A, Quero S, et al. An e-health system for the elderly (Butler Project): a pilot study on acceptance and satisfaction. Cyberpsychol Behav 2009 Jun;12(3):255-262. [doi: 10.1089/cpb.2008.0325] [Medline: 19445633]

8. Courtney K, Demiris G, Rantz M, Skubic M. Needing smart home technologies: the perspectives of older adults in continuing care retirement communities. Inform Prim Care 2008;16(3):195-201 [FREE Full text] [doi: 10.14236/jhi.v16i3.694] [Medline: 19094406 ]

9. Demiris G, Thompson H, Boquet J, Le T, Chaudhuri S, Chung J. Older adults' acceptance of a community-based telehealth wellness system. Inform Health Soc Care 2013 Jan;38(1):27-36 [FREE Full text] [doi: 10.3109/17538157.2011.647938] [Medline: 22571733]

10. Frennert SA, Forsberg A, Östlund B. Elderly people's perceptions of a telehealthcare system: relative advantage, compatibility, complexity and observability. J Technol Human Serv 2013;31(3):218-237. [doi: 10.1080/15228835.2013.814557]

11. Demiris G, Oliver DP, Dickey G, Skubic M, Rantz M. Findings from a participatory evaluation of a smart home application for older adults. Technol Health Care 2008;16(2):111-118. [doi: 10.3233/thc-2008-16205] [Medline: 18487857]

12. Mertens VA, Wille M, Theis S. Attitudes of Elderly People towards Assistive System: Influence of Amortization Barriers on the Adherence in Technically Assisted Rehabilitationthe Diffusion of Health Technologies. In: Proceedings of the 19th Triennial Congress of the International Ergonomics Association. 2015 Presented at: IEA'15; August 9-14, 2015; Melbourne, Australia URL: https://www.iea.cc/congress/2015/1592.pdf

13. Mihailidis A, Cockburn A, Longley C, Boger J. The acceptability of home monitoring technology among community-dwelling older adults and baby boomers. Assist Technol 2008;20(1):1-12. [doi: 10.1080/10400435.2008.10131927] [Medline: 18751575]

14. Mehrabian S, Extra J, Wu YH, Pino M, Traykov L, Rigaud AS. The perceptions of cognitively impaired patients and their caregivers of a home telecare system. Med Devices (Auckl) 2015;8:21-29 [FREE Full text] [doi: 10.2147/MDER.S70520] [Medline: 25552909]

15. Merilahti J, Pärkkä J, Antila K, Paavilainen P, Mattila E, Malm E, et al. Compliance and technical feasibility of long-term health monitoring with wearable and ambient technologies. J Telemed Telecare 2009;15(6):302-309. [doi:

10.1258/jtt.2009.081106] [Medline: 19720768]

16. Junnila S, Kailanto H, Merilahti J, Vainio A, Vehkaoja A, Zakrzewski M, et al. Wireless, multipurpose in-home health monitoring platform: two case trials. IEEE Trans Inform Technol Biomed 2010;14(2):447-455. [doi: 10.1109/titb.2009.2037615]

17. Bourke AK, Prescher S, Koehler F. Embedded Fall and Activity Monitoring for a Wearable Ambient Assisted Living Solution for Older Adults. In: Proceedings of the 2012 Annual International Conference of the IEEE Engineering in Medicine and Biology Society. 2012 Presented at: EMBS'12; August 28-September 1, 2012; San Diego, CA, USA p. 248-251. [doi: 10.1109/embc.2012.6345916]

18. Flynn D, van Schaik P, Blackman T, Femcott C, Hobbs B, Calderon C. Developing a virtual reality-based methodology for people with dementia: a feasibility study. Cyberpsychol Behav 2003 Dec;6(6):591-611. [doi: 10.1089/109493103322725379] [Medline: 14756925]

19. Gellis ZD, Kenaley BL, Have T. Integrated telehealth care for chronic illness and depression in geriatric home care patients: the Integrated Telehealth Education and Activation of Mood (I-TEAM) study. J Am Geriatr Soc 2014 May;62(5):889-895. [doi: 10.1111/jgs.12776] [Medline: 24655228]

20. Kurniangish, Nugroho LE, Widyawan, Lazuardi L, Non-alinsavath K. Ontology-based Context Aware for Ubiquitous Home Care for Elderly People. In: Proceedings of the 2015 2nd International Conference on Information Technology, Computer, and Electrical Engineering. 2015 Presented at: ICITACEE'15; October 16-18, 2015; Semarang, Indonesia. [doi: 10.1109/icitacee.2015.7437849]

21. Dongxia G, Wei L, Lei W. An Intelligent Reasoning Machine for the Home-based Care. In: Proceedings of the 20157 th International Conference on Electronics, Computers and Artificial Intelligence. 2015 Presented at: ECAI'15; June 25-27, 2015; Bucharest, Romania. [doi: 10.1109/ecai.2015.7301153]

22. Zhang S, McClean SI, Nugent CD, Donnelly MP, Galway L, Scotney BW, et al. A predictive model for assistive technology adoption for people with dementia. IEEE J Biomed Health Inform 2014 Jan;18(1):375-383. [doi: 10.1109/JBHI.2013.2267549] [Medline: 24403437] 
23. Hervás R, Bravo J, Fontecha J. An assistive navigation system based on augmented reality and context awareness for people with mild cognitive impairments. IEEE J Biomed Health Inform 2014 Jan;18(1):368-374. [doi: 10.1109/JBHI.2013.2266480] [Medline: 24403436]

24. Chivarov N, Shivarov S, Yovchev K. Intelligent Modular Service Mobile Robot ROBCO 12 for Elderly and Disabled Persons Care. In: Proceedings of the 2014 23rd International Conference on Robotics in Alpe-Adria-Danube Region. 2014 Presented at: RAAD'14; September 3-5, 2014; Smolenice, Slovakia. [doi: 10.1109/raad.2014.7002238]

25. Kanoh M, Oida Y, Nomura Y, Araki A, Konagaya Y, Ihara K, et al. Examination of practicability of communication robot-assisted activity program for elderly people. J Robot Mechatron 2011;23(1):3-12. [doi: 10.20965/jrm.2011.p0003]

26. Palumbo F, Ullberg J, Stimec A, Furfari F, Karlsson L, Coradeschi S. Sensor network infrastructure for a home care monitoring system. Sensors (Basel) 2014 Feb 25;14(3):3833-3860 [FREE Full text] [doi: 10.3390/s140303833] [Medline: 24573309]

27. Pollack ME, Brown L, Colbry D. Pearl: A Mobile Robotic Assistant for the Elderly. In: Proceedings of the Workshop on Automation as Caregiver: the Role of Intelligent Technology in Elder Care. 2002 Presented at: AAAI'02; 2002; Alberta, Canada URL: http://citeseerx.ist.psu.edu/viewdoc/download?doi=10.1.1.16.6947\&rep=rep1\&type=pdf

28. Sadasivam RS, Luger TM, Coley HL, Taylor BB, Padir T, Ritchie CS, et al. Robot-assisted home hazard assessment for fall prevention: a feasibility study. J Telemed Telecare 2014 Jan;20(1):3-10. [doi: 10.1177/1357633X13517350] [Medline: $\underline{24352900]}$

29. Wild K, Boise L, Lundell J, Foucek A. Unobtrusive in-home monitoring of cognitive and physical health: reactions and perceptions of older adults. J Appl Gerontol 2008;27(2):181-200 [FREE Full text] [doi: 10.1177/0733464807311435] [Medline: 19165352]

30. Osamu T, Ryu T, Hayashida A. A Smart System for Home Monitoring of People With Cognitive Impairment. In: Proceedings of the 2014 IEEE Canada International Humanitarian Technology Conference. 2014 Presented at: IHTC'14; June 1-4, 2014; Montreal, QC, Canada. [doi: 10.1109/ihtc.2014.7147550]

31. Wang D, Subagdja B, Kang Y. Towards Intelligent Caring Agents for Aging-in-place: Issues and Challenges. In: Proceedings of the 2014 IEEE Symposium on Computational Intelligence for Human-like Intelligence. 2014 Presented at: CIHLI'14; December 9-12, 2014; Orlando, FL, USA. [doi: 10.1109/cihli.2014.7013393]

32. di Lecce V, Giove A, Quarto A. Social Isolation Monitoring System via AI Approach. In: Proceedings of the 2015 IEEE Workshop on Environmental, Energy, and Structural Monitoring Systems. 2015 Presented at: EESMS'15; July 9-10, 2015; Trento, Italy. [doi: 10.1109/eesms.2015.7175887]

33. Wilson JR. Robot Assistance in Medication Management Tasks. In: The Eleventh ACM/IEEE International Conference on Human Robot Interaction. 2016 Presented at: HRI'16; March 7-10, 2016; Christchurch, New Zealand p. 643-644. [doi: 10.1109/hri.2016.7451897]

34. Amiribesheli M, Bouchachia A. Towards Dementia-Friendly Smart Homes. In: Proceedings of the 2016 IEEE 40th Annual Computer Software and Applications Conference. 2016 Presented at: COMPSAC'16; June 10-14, 2016; Atlanta, GA. [doi: 10.1109/compsac.2016.211]

35. Kurnianingsih K, Nugroho L, Widyawan, Lazuardi L, Prabuwono AS. A Predictive Positioning System Using Supervised Learning for Home Care of Older People. In: Proceedings of the 2016 International Conference on Computational Intelligence and Cybernetics. 2016 Presented at: ICCIC'16; November 22-24, 2016; Makassar, Indonesia. [doi: 10.1109/cyberneticscom.2016.7892559]

36. Yassine A, Singh S, Alamri A. Mining human activity patterns from smart home big data for health care applications. IEEE Access 2017;5:13131-13141. [doi: 10.1109/access.2017.2719921]

37. Yang C, Lu M, Tseng S. A Companion Robot for Daily Care of Elders Based on Homeostasis. In: Proceedings of the 2017 56th Annual Conference of the Society of Instrument and Control Engineers of Japan. 2017 Presented at: SICE'17; September 19-22, 2017; Kanazawa, Japan. [doi: 10.23919/sice.2017.8105748]

38. Pirzada P, White N, Wilde A. Sensors in Smart Homes for Independent Living of the Elderly. In: Proceedings of the 5th International Multi-Topic ICT Conference. 2018 Presented at: IMTIC'18; April 25-27, 2018; Jamshoro, Pakistan. [doi: 10.1109/imtic.2018.8467234]

39. Suryadevara N, Gaddam A, Rayudu R, Mukhopadhyay S. Wireless sensors network based safe home to care elderly people: behaviour detection. Sens Actuators A Phys 2012;186:277-283. [doi: 10.1016/j.sna.2012.03.020]

40. Wilson G, Pereyda C, Raghunath N, de la Cruz G, Goel S, Nesaei S, et al. Robot-enabled support of daily activities in smart home environments. Cogn Syst Res 2019 May;54:258-272. [doi: 10.1016/j.cogsys.2018.10.032] [Medline: $\underline{31565029]}$

41. Tamura T, Yonemitsu S, Itoh A, Oikawa D, Kawakami A, Higashi Y, et al. Is an entertainment robot useful in the care of elderly people with severe dementia? J Gerontol A Biol Sci Med Sci 2004 Jan;59(1):83-85. [doi: 10.1093/gerona/59.1.m83] [Medline: 14718491$]$

42. Suryadevara N, Mukhopadhyay S, Wang R, Rayudu R. Forecasting the behavior of an elderly using wireless sensors data in a smart home. Eng Appl Artif Intell 2013;26(10):2641-2652. [doi: 10.1016/j.engappai.2013.08.004]

43. Vincent C, Reinharz D, Deaudelin I, Garceau M, Talbot LR. Public telesurveillance service for frail elderly living at home, outcomes and cost evolution: a quasi experimental design with two follow-ups. Health Qual Life Outcomes 2006 Jul 7;4:41 [FREE Full text] [doi: 10.1186/1477-7525-4-41] [Medline: 16827929$]$ 
44. Pecina JL, Hanson GJ, van Houten H, Takahashi PY. Impact of telemonitoring on older adults health-related quality of life: the Tele-ERA study. Qual Life Res 2013 Nov;22(9):2315-2321. [doi: 10.1007/s11136-013-0361-5] [Medline: 23408299]

45. Kearns WD, Fozard JL, Becker M, Jasiewicz JM, Craighead JD, Holtsclaw L, et al. Path tortuosity in everyday movements of elderly persons increases fall prediction beyond knowledge of fall history, medication use, and standardized gait and balance assessments. J Am Med Dir Assoc 2012 Sep;13(7):665.e7-665.e13. [doi: 10.1016/j.jamda.2012.06.010] [Medline: 22884091]

46. Rifkin DE, Abdelmalek JA, Miracle CM, Low C, Barsotti R, Rios P, et al. Linking clinic and home: a randomized, controlled clinical effectiveness trial of real-time, wireless blood pressure monitoring for older patients with kidney disease and hypertension. Blood Press Monit 2013 Feb;18(1):8-15 [FRE Full text] [doi: 10.1097/MBP.0b013e32835d126c] [Medline: 23275313]

47. Lorenz A, Oppermann R. Mobile health monitoring for the elderly: designing for diversity. Pervasive Mob Comput 2009;5(5):478-495. [doi: 10.1016/j.pmcj.2008.09.010]

48. Vermeulen J, Neyens J, Spreeuwenberg, van Rossum E, Sipers, Habets, de Witte. User-centered development and testing of a monitoring system that provides feedback regarding physical functioning to elderly people. Patient Prefer Adherence 2013;7:843-854 [FREE Full text] [doi: 10.2147/PPA.S45897] [Medline: 24039407]

49. Khan AM, Lee Y, Lee S, Kim T. Accelerometer's position independent physical activity recognition system for long-term activity monitoring in the elderly. Med Biol Eng Comput 2010 Dec;48(12):1271-1279. [doi: 10.1007/s11517-010-0701-3] [Medline: 21052854]

50. Demiris G, Hensel BK, Skubic M, Rantz M. Senior residents' perceived need of and preferences for 'smart home' sensor technologies. Int J Technol Assess Health Care 2008;24(1):120-124. [doi: 10.1017/s0266462307080154]

51. Mahoney DF, Mahoney EL, Liss E. AT EASE: Automated Technology for Elder Assessment, Safety, and Environmental monitoring. Gerontechnology 2009. [doi: 10.4017/gt.2009.08.01.003.00]

52. Essén A. The two facets of electronic care surveillance: an exploration of the views of older people who live with monitoring devices. Soc Sci Med 2008 Jul;67(1):128-136. [doi: 10.1016/j.socscimed.2008.03.005] [Medline: 18396367]

53. Rantz MJ, Scott SD, Miller SJ, Skubic M, Phillips L, Alexander G, et al. Evaluation of health alerts from an early illness warning system in independent living. Comput Inform Nurs 2013;31(6):274-280. [doi: 10.1097/nxn.0b013e318296298f]

54. Hoof JV. Unattended autonomous surveillance in community-dwelling older adults: a field stud. Gerontechnology 2008:2008. [doi: $10.4017 /$ gt.2008.07.02.058.00]

55. Lai AM, Kaufman DR, Starren J, Shea S. Evaluation of a remote training approach for teaching seniors to use a telehealth system. Int J Med Inform 2009 Nov;78(11):732-744 [FREE Full text] [doi: 10.1016/j.ijmedinf.2009.06.005] [Medline: 19620023]

56. Wada K, Ikeda Y, Inoue K. Development and Preliminary Evaluation of a Caregiver's Manual for Robot Therapy Using the Therapeutic Seal Robot Paro. In: Proceedings of the 19th International Symposium in Robot and Human Interactive Communication. 2010 Presented at: RO-MAN'10; September 13-15, 2010; Viareggio, Itay. [doi:

10.1109/roman.2010.5598615]

57. Roger K, Guse L, Mordoch E, Osterreicher A. Social commitment robots and dementia. Can J Aging 2012 Mar;31(1):87-94. [doi: 10.1017/S0714980811000663] [Medline: 22336517]

58. Tapus A, Tapus C, Mataric M. The Role of Physical Embodiment of a Therapist Robot for Individuals With Cognitive Impairments. In: Proceedings of the 18th IEEE International Symposium on Robot and Human Interactive Communication. 2009 Presented at: RO-MAN'09; September 27-October 2, 2009; Toyama, Japan. [doi: 10.1109/roman.2009.5326211]

59. Steggel CD, Hooker K, Bowman S. The role of technology for healthy aging among Korean and Hispanic women in the United States: a pilot study. Gerontechnolog 2010;9(4):443-449. [doi: 10.4017/gt.2010.09.04.007.00]

60. Matlabi H, Parker SG, McKee K. Experiences of extra care housing residents aged fifty-five and over with home-based technology. Soc Behav Personal 2012;40(2):293-300. [doi: 10.2224/sbp.2012.40.2.293]

61. Gibson G, Dickinson C, Brittain K, Robinson L. The everyday use of assistive technology by people with dementia and their family carers: a qualitative study. BMC Geriatr 2015 Jul 24;15:89 [FREE Full text] [doi: 10.1186/s12877-015-0091-3] [Medline: 26205957]

62. Niemeijer AR, Depla MF, Frederiks BJ, Hertogh CM. The experiences of people with dementia and intellectual disabilities with surveillance technologies in residential care. Nurs Ethics 2015 May;22(3):307-320. [doi: 10.1177/0969733014533237] [Medline: 24913545]

63. Miskelly F. A novel system of electronic tagging in patients with dementia and wandering. Age Ageing 2004 May;33(3):304-306. [doi: 10.1093/ageing/afh084] [Medline: 15082438]

64. Bewernitz MW, Mann WC, Dasler P, Belchior P. Feasibility of machine-based prompting to assist persons with dementia. Assist Technol 2009;21(4):196-207. [doi: 10.1080/10400430903246050] [Medline: 20066886]

65. Fontecha J, Hervás R, Bravo J, Navarro FJ. A mobile and ubiquitous approach for supporting frailty assessment in elderly people. J Med Internet Res 2013 Sep 4;15(9):e197 [FREE Full text] [doi: 10.2196/jmir.2529] [Medline: 24004497]

66. Meiland FJ, Bouman AI, Sävenstedt S, Bentvelzen S, Davies RJ, Mulvenna MD, et al. Usability of a new electronic assistive device for community-dwelling persons with mild dementia. Aging Ment Health 2012;16(5):584-591. [doi:

10.1080/13607863.2011.651433] [Medline: 22360649] 
67. Mihailidis A, Boger JN, Craig T, Hoey J. The COACH prompting system to assist older adults with dementia through handwashing: an efficacy study. BMC Geriatr 2008 Nov 7;8:28 [FREE Full text] [doi: 10.1186/1471-2318-8-28] [Medline: $\underline{18992135]}$

68. Matthews JT, Lingler JH, Campbell GB, Hunsaker AE, Hu L, Pires BR, et al. Usability of a wearable camera system for dementia family caregivers. J Healthcare Eng 2015;6(2):213-238. [doi: 10.1260/2040-2295.6.2.213]

69. Robinson L, Brittain K, Lindsay S, Jackson D, Olivier P. Keeping In Touch Everyday (KITE) project: developing assistive technologies with people with dementia and their carers to promote independence. Int Psychogeriatr 2009;21(3):494. [doi: $\underline{10.1017 / \mathrm{s} 1041610209008448]}$

70. Skubic M, Alexander G, Popescu M, Rantz M, Keller J. A smart home application to eldercare: current status and lessons learned. Technol Health Care 2009;17(3):183-201. [doi: 10.3233/thc-2009-0551]

71. Astell AJ, Ellis MP, Bernardi L, Alm N, Dye R, Gowans G, et al. Using a touch screen computer to support relationships between people with dementia and caregivers. Interact Comput 2010;22(4):267-275. [doi: 10.1016/j.intcom.2010.03.003]

72. Wu Y, Wrobel J, Cornuet M, Kerhervé H, Damnée S, Rigaud A. Acceptance of an assistive robot in older adults: a mixed-method study of human-robot interaction over a 1-month period in the Living Lab setting. Clin Interv Aging 2014;9:801-811 [FREE Full text] [doi: 10.2147/CIA.S56435] [Medline: 24855349]

73. Hewson DJ, Jaber R, Chkeir A, Hammoud A, Gupta D, Bassement J, et al. Development of a Monitoring System for Physical Frailty in Independent Elderly. In: Proceedings of the 2013 35th Annual International Conference of the IEEE Engineering in Medicine and Biology Society. 2013 Presented at: EMBC'13; July 3-7, 2013; Osaka, Japan. [doi: 10.1109/embc.2013.6610973]

74. Prescher S, Bourke A, Koehler F, Martins A, Ferreira HS, Sousa TB, et al. Ubiquitous Ambient Assisted Living Solution to Promote Safer Independent Living in Older Adults Suffering From Co-morbidity. In: Proceedings of the 2012 Annual International Conference of the IEEE Engineering in Medicine and Biology Society. 2012 Presented at: EMBS'12; August 28-September 1, 2012; San Diego, CA, USA. [doi: 10.1109/embc.2012.6347145]

75. Pino M, Boulay M, Jouen F, Rigaud AS. 'Are we ready for robots that care for us?' Attitudes and opinions of older adults toward socially assistive robots. Front Aging Neurosci 2015;7:141 [FREE Full text] [doi: 10.3389/fnagi.2015.00141] [Medline: $\underline{26257646]}$

76. Rantz M, Skubic M, Abbott C, Galambos C, Popescu M, Keller J, et al. Automated in-home fall risk assessment and detection sensor system for elders. Gerontologist 2015 Jun;55(Suppl 1):S78-S87 [FREE Full text] [doi:

10.1093/geront/gnv044] [Medline: 26055784]

77. Torkamani M, McDonald L, Aguayo I, Kanios C, Katsanou M, Madeley L, ALADDIN Collaborative Group. A randomized controlled pilot study to evaluate a technology platform for the assisted living of people with dementia and their carers. J Alzheimers Dis 2014;41(2):515-523. [doi: 10.3233/JAD-132156] [Medline: 24643137]

78. Alexander GL, Wakefield BJ, Rantz M, Skubic M, Aud MA, Erdelez S, et al. Passive sensor technology interface to assess elder activity in independent living. Nurs Res 2011;60(5):318-325 [FREE Full text] [doi: 10.1097/NNR.0b013e318225f3e1] [Medline: 21873920]

79. Takahashi PY, Pecina JL, Upatising B, Chaudhry R, Shah ND, van Houten H, et al. A randomized controlled trial of telemonitoring in older adults with multiple health issues to prevent hospitalizations and emergency department visits. Arch Intern Med 2012 May 28;172(10):773-779 [FREE Full text] [doi: 10.1001/archinternmed.2012.256] [Medline: 22507696]

80. Reder S, Ambler G, Philipose M. Technology and Long-term Care (TLC): A pilot evaluation of remote monitoring of elders. Gerontechnology 2010;9(1):18-31. [doi: 10.4017/gt.2010.09.01.002.00]

81. Kleinberger T, Becker M, Ras E, Holzinger A, Müller P. Ambient intelligence in assisted living: enable elderly people to handle future interfaces. In: Universal Access in Human-Computer Interaction. Ambient Interaction. Berlin, Heidelberg: Springer; 2007:103-112.

82. Jämsä T, Kangas M, Vikman I, Nyberg L, Korpelainen R. Fall detection in the older people: from laboratory to real-life. Proc Estonian Acad Sci 2014;63(3):341-345. [doi: 10.3176/proc.2014.3.08]

83. Leuty V, Boger J, Young L, Hoey J, Mihailidis A. Engaging older adults with dementia in creative occupations using artificially intelligent assistive technology. Assist Technol 2013 Apr 3;25(2):72-79. [doi: 10.1080/10400435.2012.715113] [Medline: 23923689]

84. Lin CC, Lin PY, Lu PK, Hsieh GY, Lee WL, Lee RG. A healthcare integration system for disease assessment and safety monitoring of dementia patients. IEEE Trans Inf Technol Biomed 2008 Sep;12(5):579-586. [doi: 10.1109/TITB.2008.917914] [Medline: 18779072]

85. Surie D, Laguionie O, Pederson T. Wireless Sensor Networking of Everyday Objects in a Smart Home Environment. In: Proceedings of the 2008 International Conference on Intelligent Sensors, Sensor Networks and Information Processing. 2008 Presented at: ISSNIP'08; December 15-18, 2008; Sydney, Australia. [doi: 10.1109/issnip.2008.4761985]

86. LWW Journals. 2015. JBJS, Inc Journals Level of Evidence URL: https://journals.lww.com/jbjsjournal/Pages/ Journals-Level-of-Evidence.aspx [accessed 2019-07-01]

87. The Centre for Evidence-based Medicine (CEBM). 2011. The Oxford 2011 Levels of Evidence URL: https://www.cebm.net/ wp-content/uploads/2014/06/CEBM-Levels-of-Evidence-2.1.pdf [accessed 2019-07-01] 
88. Braun V, Clarke V. Using thematic analysis in psychology. Qual Res Psychol 2006;3(2):77-101. [doi: 10.1191/1478088706qp063oa]

89. Demiris G, Oliver DP, Giger J, Skubic M, Rantz M. Older adults' privacy considerations for vision based recognition methods of eldercare applications. Technol Health Care 2009;17(1):41-48. [doi: 10.3233/THC-2009-0530] [Medline: 19478404]

90. Do HM, Pham M, Sheng W, Yang D, Liu M. RiSH: A robot-integrated smart home for elderly care. Robot Auton Syst 2018;101:74-92. [doi: 10.1016/j.robot.2017.12.008]

91. Elakkiya J, Gayathri KS. Progressive Assessment System for Dementia Care Through Smart Home. In: Proceedings of the 2017 International Conference on Algorithms, Methodology, Models and Applications in Emerging Technologies. 2017 Presented at: ICAMMAET'17; February 16-18, 2017; Chennai, India. [doi: 10.1109/icammaet.2017.8186713]

92. Ferreira F, Dias F, Braz J, Santos R, Nascimento R, Ferreira C, et al. Protege: a mobile health application for the elder-caregiver monitoring paradigm. Procedia Technol 2013;9:1361-1371. [doi: 10.1016/j.protcy.2013.12.153]

93. Cheng H, Zhuang W. Bluetooth-enabled in-home patient monitoring system: early detection of Alzheimer's disease. IEEE Wireless Commun 2010;17(1):74-79. [doi: 10.1109/mwc.2010.5416353]

94. Chen BR, Patel S, Buckley T, Rednic R, McClure DJ, Shih L, et al. A web-based system for home monitoring of patients with Parkinson's disease using wearable sensors. IEEE Trans Biomed Eng 2011 Mar;58(3):831-836. [doi:

10.1109/TBME.2010.2090044] [Medline: 21041152]

95. Hori T, Nishida Y, Aizawa H. Sensor Network for Supporting Elderly Care Home. In: Proceedings of 2004 IEEE Sensors. 2004 Presented at: SENSORS'04; October 24-27, 2004; Vienna, Austria. [doi: 10.1109/icsens.2004.1426230]

96. Cook DJ. Health monitoring and assistance to support aging in place. J Univers Comput Sci 2006;12(1). [doi: 10.3217/jucs-012-01-0015]

97. Xiao HW, Da QZ, Tao G. Ontology Based Context Modeling and Reasoning using OWL. In: Proceedings of the Second IEEE Annual Conference on Pervasive Computing and Communications Workshops. 2004 Presented at: PERCOMW'04; March 14-17, 2004; Orlando, FL, USA. [doi: 10.1109/percomw.2004.1276898]

98. Jeon H, Park S, Choi J, Lim Y. Ontology-based dementia care support system. Conf Proc IEEE Eng Med Biol Soc 2018 Jul;2018:3318-3321. [doi: 10.1109/EMBC.2018.8512965] [Medline: 30441099]

99. Ramoly N, Bouzeghoub A, Finance B. A framework for service robots in smart home: an efficient solution for domestic healthcare. IRBM 2018;39(6):413-420. [doi: 10.1016/j.irbm.2018.10.010]

100. Cesta A, Cortellessa G, Rasconi R. Monitoring elderly people with the robocare domestic environment: interaction synthesis and user evaluation. Comput Intell 2011;27:60-82. [doi: 10.1111/j.1467-8640.2010.00372.x]

101. Libin A, Cohen-Mansfield J. Therapeutic robocat for nursing home residents with dementia: preliminary inquiry. Am $\mathbf{J}$ Alzheimers Dis Other Demen 2004;19(2):111-116. [doi: 10.1177/153331750401900209] [Medline: 15106392]

102. Demiris G, Iribarren SJ, Sward K, Lee S, Yang R. Patient generated health data use in clinical practice: a systematic review. Nurs Outlook 2019;67(4):311-330. [doi: 10.1016/j.outlook.2019.04.005] [Medline: 31277895]

103. Filan SL, Llewellyn-Jones RH. Animal-assisted therapy for dementia: a review of the literature. Int Psychogeriatr 2006 Dec;18(4):597-611. [doi: 10.1017/S1041610206003322] [Medline: $\underline{\text { 16640796] }}$

\section{Abbreviations}

AI: artificial intelligence

VR: virtual reality

Edited by J Wang; submitted 10.07.19; peer-reviewed by R Yang, Y Du; comments to author 06.09.19; revised version received
08.09.19; accepted 05.10.19; published 29.11.19
Please cite as:
Sapci AH, Sapci HA
Innovative Assisted Living Tools, Remote Monitoring Technologies, Artificial Intelligence-Driven Solutions, and Robotic Systems for
Aging Societies: Systematic Review
JMIR Aging 2019;2(2):e15429
URL: $\underline{\text { http://aging.jmir.org/2019/2/e15429/ }}$
doi: $10.2196 / 15429$
PMID: $\underline{31782740}$

CA Hasan Sapci, H Aylin Sapci. Originally published in JMIR Aging (http://aging.jmir.org), 29.11.2019. This is an open-access article distributed under the terms of the Creative Commons Attribution License (https://creativecommons.org/licenses/by/4.0/), which permits unrestricted use, distribution, and reproduction in any medium, provided the original work, first published in JMIR 
Aging, is properly cited. The complete bibliographic information, a link to the original publication on http://aging.jmir.org, as well as this copyright and license information must be included. 